\title{
Uygur Şairi Muhemmetcan Raşidin ve Şiir Dünyası ${ }^{1}$
}

DOI NO: 10.5578/JSS.7135

Ahmet Karaman ${ }^{2}$

\section{Özet}

Toplumların yaşayışında edebiyatın önemli bir yeri vardır. Edebi eserler toplumun yaşantısını yansitan ayna gibidir. Bu nedenle edebi şahsiyetler toplumlar için birer değerdir. Bu değerlerden biri de Uygur şairlerinden Muhemmetcan Raşidin'dir. Muhemmetcan Raşidin, 15 Haziran 1940 yllında Gulca nahiyesinin Onyaryüzi köyündeki bir çiftçi ailesinde dünyaya gelmiştir. İlk ve ortaokul eğitimini Gulca'da tamamlayan şair, 1955 ile 1958 yllları arasında Sincan Köy Ekonomi Lisesinde eğitim görmüştür. 1959 yılında Piçan nahiyesinde yeniden eğitim almıştır. 1960 ile 1968 yılları arasında Çapçal ve Gulca nahiyelerinde memurluk, teknik eleman, kâtiplik ve ögretmenlik görevlerinde bulunmuştur. 1968 ile 1983 yılları arasında haksız yere edebi faaliyetlerden mahrum edilmiştir.

Muhemmetcan Raşidin'in edebi faaliyetleri 1958 yllında Ili Gazetesi'nde yayımlanan "İli Deryası" adlı şiiriyle başlamıştır. Özellikle 1980'lerden sonra sanat faaliyetlerinde gözle görünür bir başarı yakalamıştır. Muhemmetcan Raşidin'in binden fazla şiiri "Kakkuk Güli", "Yillar İzi", "Künler Albomi", "Ana Yer Qesidisi", "Ömür Ilhamliri", "Hayat Dégen Mana Şu" adlarını taşlyan şiir kitaplarında bir araya getirilmiştir.

Bu yazımızda, Muhemmetcan Raşidin'in Sincan Halk Neşriyatı tarafindan 2008 yılında "Ana Tag̀lar" adıyla yayımlanan ve içinde elli yedi şiirin bulunduğu şiir kitabını değerlendirmeye çalışacağız. Bu şiirlerin en eskisi 1984, en yenisi ise 2004 yılında yazılmıştır. İnceleyeceğimiz şiirleri seçerken Muhemmetcan Raşidin'in kullandiğ dil ve üslûp özelliklerini yansitan eserleri dikkate aldik.

Anahtar kelimeler: Uygur şairi, şiir, dil ve üslûp

1 Bu makale 5. Dünya Dili Türkçe Sempozyumu'nda sunulmuş ve yayımlanmamış bildirinin genişletilmiş biçimidir.

2 Yrd. Doç. Dr., Afyon Kocatepe Üniversitesi, Fen Edebiyat Fakültesi, Türk Dili ve Edebiyatı Bölümü. ahkaraman03@gmail.com 


\title{
Uyghur Poet Muhemmetcan Raşidin and His Sense of Poetry
}

\begin{abstract}
Literature has an important place in social life. Literary works are like mirrors which reflect the society. For this reason, literary people are valuable of the society. One of these values people is Muhemmetcan Raşidin, an Uyghur poet. Muhemmetcan Raşidin was born on June $15^{\text {th }} 1940$. He completed his primary and secondary education in Gulca and he was educated at Sincan Rural Economy High School between 1955 and 1958. He was unjustly deprived of literary activities between the years of 1968 and 1983.

The literary activities of Muhemmetcan Raşidin started with the poem named 'Ili Deryasi' which was published in 1958. Especially after the 1980's he was again renowned. More than a thousand poems of Muhemmetcan Raşidin have been gathered in some poetry books such as "Kakkuk Güli", "Yillar İzi", "Künler Albomi", "Ana Yer Qesidisi", "Ömür Illhamliri", "Hayat Dégen Mana Şu".

In this article, we are going to try to evaluate the volume of poetry Ana Taglar which was printed by the Publications of the Sincan Public in 2008. There are fifty seven poems in the book.

While selecting the poems to analyze in this article, we paid attention to works which reflects language and style of Muhemmetcan Raşidin.

Key words: Uyghur poet, poem, language and style

\section{Giriş}

Uygurlar, Çin Halk Cumhuriyeti'nin Şincan Uygur Özerk Bölgesi ile Kazakistan, Kırgızistan, Özbekistan, Türkmenistan, Türkiye, ABD, Almanya ve Avustralya'da yaşamaktadırlar. Çin Hükümeti Doğu Türkistan'daki Uygur Türklerinin gerçek nüfusunu gizleme politikası güttüğünden nüfusları hakkında kesin bir rakam söylemek mümkün değildir.

Çin askerlerinin Doğu Türkistan’a girdiği 1755-1865 yılları isyanlarla geçen Birinci Çin İstilası Devri'dir (Kurban,1995: 72). Bu dönemden başlayarak günümüze kadar devam eden süreçte Doğu Türkistan çalkantılı, sıkıntılı bir coğrafya olagelmiştir. Bu siyasi buhranlar kimi zaman edebi faaliyetlerin yasaklanması kimi zaman da sanatçıların belirli politikalar doğrultusunda yayına zorlanması biçiminde edebiyata da yansımıştır. Bunların en somut ve derin izler bırakanı ise Çin Hükümetinin 1966 yılında ilan ettiği Büyük Kültür Devrimi’ dir. Bu dönem, özellikle Uygur Türklerinin bütün kültürel ve dinî değerlerinin yok edilmeye çalışıldığı, sanatçıların kalemlerinin kırıldığı ve komünist yönetimi övmeye zorlandığ 1 kültürel bir tahribat dönemidir.
\end{abstract}


Halkın duygularını, görüşlerini, tarihi gerçekleri yazan yazarlar "milliyetçi", "ayrılıkçı", "Türkçü" tabirleriyle karalanarak cezalandırılmış, hapislere atılmıştır (Kaşgarlı, 2012: 348).

Büyük Kültür Devrimi'nden önce de Uygur aydınları baskılara, zulme maruz kalmışlar ancak bağımsızlık düşüncesinden asla ödün vermemişlerdir. Bunun en güzel örneğini Lutpulla Mutellip’te görmekteyiz. Lutpulla Mutellip, Milliyetçi Çin Partisi Gomindan tarafından hapishanede hunharca öldürülür. Ancak son nefesinde bile Lutpulla Mutellip, kanıla hapishane duvarlarına:

\section{Bu keñ zémin men üçün boldi dozax,}

Yaş gülümni xazan qildi qanxor eblex.

"Bu geniş topraklar benim için oldu cehennem,

Taze gülümü hazan etti kan içici alçak" (Karaman, 2011: XXXII)

dizelerini yazarak özgürlük mücadelesini kanının son damlasına kadar sürdürdüğünü trajik biçimde ortaya koymuştur.

Mücadelenin hiç bitmediği bu coğrafya, pek çok şairin, yazarın yetiştiği bir kültür havzasıdır. Burada kalemine pranga vurulamayacak pek çok sanatçı yetişmiştir. Bunlardan biri de Muhemmetcan Raşidin'dir.

\section{Hayatı}

Uygur şairi Muhemmetcan Raşidin 15 Haziran 1940'ta Gulca nahiyesinin Onyaryüzi köyünde bir çiftçi ailesinin çocuğu olarak dünyaya gelmiştir. İlk ve orta öğrenimini Gulca'da tamamlayan şair 1955-1958 y1lları arasında Sincan Teknik Lisesi'nde okumuştur (Komisyon, 2006: 386). 1959 yılında beş ay süreyle Piçan nahiyesinde yeniden eğitim gören Muhemmetcan Raşidin 1960'tan 1968 y1lına kadar Çapçal ve Gulca nahiyelerinde memur, teknik eleman, kâtip ve eğitimci olarak görev yapmıştır (İbrahim, 2011: 1). 1968 yılında Büyük Kültür Devriminin olumsuz sonuçlarından etkilenmiş haksız yere suçlanarak edebî faaliyeti kesintiye uğramışır. 1983 yılında suçlamalardan aklanıp Gulca nahiyesinde dil ve edebiyat muallimi olarak çalışmaya devam etmiştir.

Şiire 1958'de yazdığı İli Deryasi (İli Denizi) adlı şiirin İli Gazetesi'nde yayımlanmasıyla başlayan şair, edebî sahadaki yetkinliğini asıl olarak 1980 'lerden sonra yazdığ 1 şiirlerinde gösterir. Onun şimdiye kadar yazdığ 1 binden fazla şiir Kakkuk Güli (Guguk Gülü), Yillar İzi (Yılların İzi), Künler 
Albomi (Günlerin Albümü), Ana Yer Qesidisi (Ana Yer Kasidesi), Ömür Illhamliri (Ömür İlhamları), Hayat Dégen Mana Şu (Hayat Dediğin İşte Bu) adlı kitaplarda toplanarak yayımlanmıştır.

\section{2. Şiir Dünyası}

İli Denizi adını taşıyan şiirle edebiyat dünyasına adım atan Muhemmetcan Raşidin uzunca bir süre durgunluk dönemi yaşamıştır. 1966 ile 1980'li yılların başına kadar süren bu sessizlik dönemini çeşitli sebeplere bağlayabiliriz. Daha çocuk yaşlarda edebî zevke sahip olan şair çok istediği hâlde sosyal bir alanda eğitim görememiş teknik bir okulda eğitimini tamamlamıştır. Çalıştığ iş kollarının teknik sahalar olması sanatçının edebî faaliyetlerini engellemiş olsa da bu uzun süren sessizliği siyasî bir sebebe bağlamak daha doğru olacaktır.

8 Ağustos 1966 tarihinde Pekin yönetiminin ilan ettiği "Büyük Kültür Devrimi" aslında Pekin yönetim kadrolarının bir iç çekiş̧mesidir (Kaşgarlı, 2012: 348). Bu iç çekiş̧me Doğu Türkistan'da daha sancılı yaşanmış yazarlar, düşünürler, şairler ya hapislere atılarak işkence görmüşler ya da sürgüne gönderilmişlerdir. Kültür Devrimi sırasında pek çok sanatçı özgün eserler verememiş Pekin yönetimini övmeye zorlanmışlardır.

Büyük Kültür Devrimi'nin olumsuz etkilediği kişilerden biri de Muhemmetcan Raşidin'dir. Haksız yere suçlanarak edebî faaliyetleri engellenmiş adeta kafese hapsolmuştur. Kendisi bu durumu "Ben Geliyorum İki Gözüm Yaş" şiirinde şöyle ifade eder:

Ben geliyorum selam sana İli,

Keklik gibi kafesten kurtuldum.

Ben geliyorum guguk gibi şakıyarak

Zeynep için ayrılıktan kurtuldum

Ben geliyorum iki gözüm yaş,

Onun sebebi iki hem sirrı.

Biri mutluluktan biri elemden

Yazsam kitap olur her biri 
Şairin şiirde zikrettiği Zeynep, efsanevî Guguk kuşunun eşidir. Şair, efsanevî iki sevgili kuşun vuslatıla kendinin edebî faaliyetlerine tekrar başlaması arasında da bir benzerlik ilgisi kurmaktadır.

1976'da Büyük Kültür Devrimi'nin sona ermesiyle yeniden yazmaya başlamıştır. Muhemmetcan Raşidin 1980'li yıllarda Çağdaş Uygur edebiyatının oluşmasında önemli rol oynayan edebî şahsiyetlerden biri olmuştur. Şiirlerinde insan, toplum, tabiat önemli yer tutar. Ancak 2000 yılından sonra yazdığ daha çok aşk temalıdır.

Muhemmetcan Raşidin "Şiir, Şöhret ve Ben" adlı şiirinde kalemini hangi amaçla kullandığını oldukça güzel ifade etmiştir:

Qelemni alginim yoq şöhret üçün,

Yükseklik talaşmaymen héçkimdinmu

Muradim - elniñ mendin memnunluqi,

Epsuslar añligum yoq héç dildinmu.

Kalemimi şöhret için (ele) almadım

Üstünlük tartışmam hiçkimseyle de

Arzum, halkın benden memnun olmas

Maalesef dinleyenim yok gönülden

Görüldüğü gibi şair mevki, şöhret peşinde değildir. O, sanatını halkın yararına kullanma amacındadır. Ancak kendini anlayanın olmaması da şairi rahatsız eder. Şair şöhret düşkünlüğünü bir illet olarak görüp onu şeytan diye vasiflandirır:

Şeytandur dosti şöhretpereslikniñ,

Ündimes köñlüm méni şu illetke.

Eqlini nam-ataqqa bergenlerniñ

Qelbini oxşitimen bir zulmetke.

Şeytandır dostu şöhretperestliğin

Çağırmaz gönlüm beni o hastalığa 
Aklını şan ve şöhrete verenlerin

Kalbini benzetirim bir karanlığa

Muhemmetcan Raşidin, Uygur edebiyatında silinmez izler bırakmış bir şair olan Lutpulla Mutellip gibi Nevâ̂i'ye hayrandır ve onun izinden gittiğini iddia eder:

Qolumda şair Lutun tutqan qelem

İzidin mañdim menmu Nevaiyniñ (Karaman, 508: 2011).

Elimde şair Lutun tuttuğu kalem

İzinden yürüdüm ben de Nevâî'nin

Muhemmetcan Raşidin'in şiirlerinde görülen temalardan biri de "vatan"dır. Vatan Dağları adlı şiirinde dağları çeşitli benzetmelerle ulvî bir hüviyete büründürür:

\author{
Veten Taġliri \\ Heyvetlik bu tagilar - veten tagiliri, \\ Atiler qeddi u, anilar hösni \\ Taşliri tutiya, bulaqliri süt, \\ Tag̉lardin başlidim veten söyüşni \\ Vatan Dağları \\ Heybetli bu dağlar - vatan dağları \\ Ataların duruşu o, anaların güzelliği \\ Taşları tûti, pınarları süt, \\ Dağlardan başladım vatanı sevmeye
}

Şair dağların heybetli görünüşünü ataların boyuna, duruşuna; güzelliğini ise anaların güzelliğine benzeterek bir kutsallık atfetmiş̧ir. Taşlarını da papağana benzeterek işitme duyularına yönelmiştir. Pınarlarını ise süte benzeterek berraklığı, saflığı ve temizliği vurgulamıştır. Vatan sevgisini dağlardan 
başlatması ise zor zamanları çağrıştırarak en zor günde vatana bağlılı̆̆ın önemine dikkat çekmiştir.

Muhemmetcan Raşidin'in şiirlerinde dostluk ve muhabbet duygusu önemli bir yer tutar. Dostları için iyi dilekler tutarken sıkıntıları hep kendine saklar. Bu ondaki vefa duygularının ne denli güçlü olduğunu göstermesi bakımından önemlidir:

Yaman künler men bilen ketkey,

Yaxşi künler sen bilen bolsun

Menla tartay tiken derdini,

Qizilgüller sen bilen bolsun

Kötü günler benimle gidecek

İyi günler seninle olsun

Ben de çekeyim diken derdini

Kızılgüller seninle olsun

Muhabbet de Ulu Bir Mektep adlı şiirinde muhabbeti, yüce bir mektebe benzeterek âşıklar hep doğru konuşur, vefalı yazar ve Hakk'ı söylerler. Bu nedenle gönül vermeyi hatta aşktan mecnun olup gezmeyi günah saymamak gerekir. Aşkla geçen her zaman dünyadaki en huzurlu geçen andır:

Muhebbetmu ulug bir mektep,

Aşiqliqni sözleydu heq dep.

Yazġanliri vapa desturi,

Qilganliri qedimdin heq gep.

Muhabbet de yüce bir mektep

Aşkı anlatır hak deyip

Yazdıkları vefa desturu

Yaptıkları ezelden hak söz 
Gunah démes könül bergenni,

Kakkuk - Zeynep bolup yürgenni.

Bu dunyaniñ huzuri deydu

Şu mektepte ötken her demni.

Günahkâr saymaz gönül vereni,

Guguk-Zeynep olup gezeni

Bu dünyanın huzuru der

Bu mektepte geçen her anı

Kültürümüzdeki "lokmasını paylaşmak" anlayışını Muhemmetcan Raşidin'in şiirlerinde de görüyoruz:

Bir nan tapsam, yérimi séniñ,

Teñ ölimiz açliqtin ölsek

Yalg̀uz külüs yaxşi iş emes,

Teñ külimiz toqluqtin külsek

Bir ekmek bulsam, yarısı senin

Birlikte öleceğiz açlıktan ölsek

Tek başına gülmek doğru değil

Birlikte güleceğiz tokluktan gülsek

Şair, Dostlara adlı şiirinde vefa duygularını dile getirirken açlık-tokluk, ölmek ve gülmek zıtlıklarından faydalanıyor. Şaire göre gerçek dostluk hem yaşamda hem de ölümde birlikte olmaktır.

Dosta ve dostluğa vefayı bir düstur olarak gören şair geçmişte çile çekmiş atalarını da vefa ile hatırlamayı ihmal etmez. Ne Bilsin adlı şiirinde genç kuşağı geçmişin elemini anlamadığ i için eleştirir. Şair bu yönüyle toplumun dertlerinden uzak olmadığını, toplumla iç içe olduğunu bu dizelerde de açıkça ortaya koyar: 
Atilar çekken riyazetni

Davan körmey, tay ne bilsun?!

Gerib nedur, musapir kim,

Paragatte bay ne bilsun?!

Kün qattiqi qelenderlik,

Aç derdini toq ne bilsun?!

Veci néme köz yaşlarniñ

Gem-qaygusi yoq ne bilsun?!

Atalar çekmiş çileyi

Yokuş görmeyen tay ne bilsin?!

Garip nedir, misafir kimdir,

Mutlu zengin ne bilsin?!

Zamanın zorluğu çile çekmek

Açın derdini tok ne bilsin

Gözyaşlarının sebebini

Derdi olmayan ne bilsin

Görülmektedir ki şair kalemini gerçekten şöhret için ele almamıştır. O, toplumun derdiyle dertlenen bir kişidir. Dizelerinde her zaman bir sıkıntı, bir çile, bir gözyaşıyla karşılaşmak mümkündür.

Muhemmetcan Raşidin, yaşadığı çileli hayatı dizelerine ilmek ilmek işlemiştir. $\mathrm{Bu}$ nedenle lirizm şiirlerinde önemli bir yer tutar. Gönlüm şiirinde yalancı sevdalara sitem vardır:

Éçil, dése aldirap éçilma, köñüm,

Marcan bolsañ yipiñden çéçilma, köñlüm.

Biri séni aldaydu: "Aşiqiñ biz" dep,

Biri yalġan yiğlisa, éçinma, köñüm.

Açıl dese acele edip açılma gönlüm,

Mercan olsan ipinden saçılma gönlüm.

Biri seni aldatır: "Sana aşığız" diyerek,

Biri yalandan ağlasa acıma, gönlüm. 
Yügürüp yürme keynidin çirayliqlarniñ,

Sadaqetsiz seplerge qétilma, köñlüm.

Kimlerniñdur meylige bérip bariñni,

Örük bolup şaxlardin qéqilma, köñlüm.

Koşup durma arkasından güzellerin,

Sadakatsiz saflara katılma gönlüm.

Kimlere meylettin her şeyini verip,

Erik olup dallardan silkelenme gönlüm.

Muhemmetcan Raşidin, hurafeye, çalışmadan tevekkül etmeye karşı çıkmıştır. Muhammes biçiminde yazdığı bir şiirinde hurafenin topluma nasıl zarar verdiğini şöyle ifade etmiştir:

Ara ayda toy qilsam, kétermişmen ayrilip,

Şamda xoraz çillisa, ölermişmen caylinip,

Şundaq dédi bir mollam maña etey qayrilip:

"Qegंez tutsañ teretke qalarmişsen aylinip..."

Layiqlaşmay zamang்a, layg்a patqan xurapat.

Ara ayda düğün etsem, ayrılırmışım

Gece horoz ötse, ölürmüşüm

Böyle dedi bir molla bana dönerek

Taharette kâğıt kullanırsan dönüp durursun

Zamana uygun değil çamura batan hurafe

Bendin birinci dizesinde ifade edilen ara ay Ramazan Bayramı ile Kurban Bayramı arasında kalan zaman dilimidir. $\mathrm{Bu}$ süreçte yapılan düğünlerde mutluluğun uzun süreli olmayacağı ayrıllğın hemen geleceği inanc1 eleştirilmiştir. Anadolu coğrafyasında yaşayan Türk toplumunda da aynı hurafeyi görüyoruz. Ramazan bayraminin kutlandiğg şevval ile, kurban bayraminın kutlandiğg zilhicce arasındaki zilkadeyi, halk, aralık adiyla adlandirır; bu ayda evlenme halk inanışında uğurlu sayllmaz (Boratav, 2013: 
236). Şair burada cehalete saplanmış halkın boş inançlar peşinde koşmasını eleştirmiştir.

Gece vakti öten horozun ölümün habercisi olduğu inancı da eleştirilen bir başka hurafedir. Aynı hurafeyi Anadolu'da da görüyoruz. Ancak horoz motifinin yerinde baykuş motifi daha yaygın kullanılmaktadır. Yine de pek çok yerde gece vakti öten horozun uğursuzluk getireceği düşünülerek kesilmesine karar verilir.

Tuvalet kâğıdının temizlik malzemesi olarak kullanılmaya başladığı dönemlerde dinî yönden sakıncalı görülüp uygun olmadığı yönünde pek çok tartışmanın yaşandığı bir gerçektir. Kutsal bir eşya olan kâğıdın tuvalette temizlik malzemesi olarak kullanılmasının insanların başına dertler açacağı inancı Uygur Türkleri ile Anadolu Türkleri arasında ortak bir inanıştır. Şairin dizelerinde bunu açıkça görebiliyoruz.

Muhemmetcan Raşidin, hurafeye bakış noktasında Mehmet Akif'le de benzerlikler göstermektedir. Akif, Fatih Kürsüsü'nde:

"Çalış dedikçe din, çallş̧madın durdun,

Onun hesabina birçok hurafe uydurdun!"

dizelerinde tembelliğin, dini doğru algılamamanın hurafeye yol açtığını ifade ederek miskinliğin tevekkülle karıştırılmamasını istemiştir.

\section{1. Şiirlerinde Şekil Özellikleri}

Muhemmetcan Raşidin'in incelediğimiz "Ana Tağlar" adlı seçme şiirlerinden oluşan kitapta yer alan şiirlerden 48'i dörtlük, 3'ü muhammes, 5'i tek bentten oluşmaktadır. Ayrıca 37 şiir beyit nazım birimiyle yazılmıştır.

\subsection{Vezin}

İncelediğimiz elli yedi şiirin tamamında hece ölçüsü kullanılmıştır. Bu şiirlerde 7'li, 8'li, 9'lu, 11'li, 16'lı hece ölçüleri tercih edilmiştir. Ancak bazı dizelerde hece sayısının eşit olmadığı görülür. Örneğin Ne Bilsun adlı şiirde 8'li hece kullanıldığı hâlde ilk dize dokuz heceden oluşmaktadır.

\subsection{Kafiye Çeşitleri}

Muhemmetcan Raşidin, ahengi sağlamak için kafiye ve rediften sıkça yararlanmıştır. Şiirlerinde en çok tam kafiyeyi kullanmıştır. Zengin ve tunç 
kafiyeyi birkaç şiirde kullanmıştır. Yarım kafiyeyi pek tercih etmediği görülür. Redifler önemli bir yer tutar.

Tam kafiye örnekleri:

Kün qattiki qelenderlik,

Aç derdini toq ne bilsun?

Veci néme köz yaşlarniñ,

Ġem-qayġusi yoq ne bilsun?

Kimge berseñ meyli idi,

Qolliriñda bir dan bolsam.

Tapar idim ulugiluqni,

Özüñ yaqqan bir nan bolsam.

Tunç kafiye örneği:

Maña ölüm tilepsen axşam

Bériptu dep méni toylarġa

Künçilikiñ qattiqken eceb,

Sélip qoyduñ méni oylarġa

Zengin kafiye örneği:

Yamanlar amraq kélur öseklerge,

Yaxşilar mohtac emes céseklerge.

Qutrigan hayvan bolup dessep yürer

Ösekler yéñi quyġan késeklerge 


\title{
3. Dil ve Üslup
}

Şiir dili, bir milletin gündelik yaşantısı içinde kullandığı ortak dil içinde özel bir sanat dilidir. Şairin en önemli görevlerinden biri ana dilini sevmesi, en ince ayrıntılarına kadar bilmesi, onu en işlek ve kıvrak biçimde kullanmaya çalıșmasıdır (Çetin, 2010:167). Muhemmetcan Raşidin, şiirlerinde halkın anlayabileceği yalın bir dil kullanmıştır. Şiirlerinde kullandığı Arapça, Farsça kökenli kelimeler halkın eskiden beri kullandığı anlamı herkes tarafından bilinen kelimelerdir. Muhemmetcan Raşidin şiirlerinde dilin sadeliğinin yanında ahenkli olmasına da önem vermiştir. Ahengi, kafiye ve redifi çok başarılı bir biçimde kullanarak sağlamıştır.

Şiirlerinde kullandığı "ekmeğini paylaşmak" (Bir nan tapsam, yérimni séniñ), "Tok açın hâlini bilmez." (Aç derdini toq ne bilsun?), "aç tok gezmek" (aç-toq yürer) gibi deyim ve atasözleri dilinin akıcılı̆̆ına katkı sağlayan unsurlardandır.

Üslup, bir kişinin duygu, düşünce ve hayallerini sözle ya da yazıyla kendine has bir tarzda dile getiriş, ifade ediş biçimidir (Çetin, 2010: 197). Muhemmetcan Raşidin kullandığı temalara göre hiciv üslubu, lirik üslup, konuşma üslubu gibi farklı üsluplar kullanmışsa da asıl olarak yalın üslubu tercih eder. Sen Mendek Bolalamsen "Sen Benim Gibi Olabilir misin?", Vay Dad "Vay Baba" adlı şiirlerinde hiciv üslubunu tercih ederken; Yari Yoqni Biçare Deñlar "Sevdiği Olmayana Biçare Deyiniz", Dostlarg̉a "Dostlara" adlı şiirlerinde konuşma üslubunu tercih etmiştir.

\section{4. Şiirlerinden Örnekler}

\author{
NE BILLSUN \\ Atilar çekken riyazetni \\ Davan körmey, tay ne bilsun?! \\ Gerib nedur, musapir kim, \\ Paraġatte bay ne bilsun?! \\ Kün qattiqi qelenderlik, \\ Aç derdini toq ne bilsun?! \\ Veci néme köz yaşlarniñ, \\ Gem-qaygusi yoq ne bilsun?!
}


Çañqap yatqan çöl derdini

Bag̀lardiki gül ne bilsun?!

Yamg்ur qedrini elmisaqtin

Çöller bilmey, köl ne bilsun?!

\section{NE BÍLSİN}

Atalar çekmişs sıkıntıyı

Yokuş görmeyen tay ne bilsin?

Garip nedir, misafir kim,

Mutlu zengin ne bilsin?

Günün zorluğu çile çekmek

Açın derdini tok ne bilsin?

Sebebi nedir gözyaşlarının

Gamı kaygısı olmayan ne bilsin?

Suya hasret çöl derdini

Bağlardaki gül ne bilsin?

Yağmurun kıymetini ezelden beri

Çöller bilmiyor göl ne bilsin?

\section{ADEMLER ULUं}

Künlerniñmu her xili bardur

Güllerniñmu her xili bardur

Ademlerdin rencime, köñüm

Ularniñmu ser xili bardur

Tilemçige nan bérir biri

Kepterlerge dan bérer biri

Zörür bolsa, qan bérir biri

Hetta canni bergini bardur 
Yatmiqi bar àgrip saqniñmu, Solmiqi bar seyligahniñmu

Dölet ketse, hetta şahniñmu

Döndin qoray termiki bardur

Dunya tilsim, ademler ulug

Tiriklikke adem özi tug.

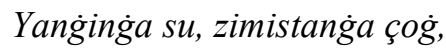

Şuña güzel menzili bardur.

\section{İNSANLAR YÜCEDİR}

Günlerin de her çeşidi vardır

Güllerin de her çeşidi vardır

İnsanlardan incinme, gönlüm

Onların da değerlisi vardır

Dilenciye ekmek verir biri

Güvercinlere yem verir biri

Zorda kalsa kan verir biri

Hatta canını veren vardır.

Hastalanıp yatması var sağlamın da

Sararıp solması var gezinti yerinin

Devlet gitse, hatta şahın da

Tepesi solan bitkinin başağı vardır

Dünya tılsımlı, insanlar yüce

Sağlık için insanın kendisi tuğ

Yangına su, kışa kor ateş

Bunun için güzel mekânı vardır 


\section{YIRAQLAR'ंA KETME, EZIZIIM}

Yiraqlarga ketme, ezizim,

Yiraq yerniñ teşvişi tola

Yaxşi emes ayrilip yaşaş

Ayrilganniñ köz yéşi tola.

Yiraqlarga ketme, ezizim,

Baralmaymen keyniñdin izdep.

Yiraq yerde séni düşmenler

Azduridu: "Aşiqiñ biz!" dep.

Yiraqlarga ketme, ezizim,

Yiraq yerdin kelmikiñ testur.

Gemliriñde méniñ bu köñlüm

Sen kelgüçe tinç emestur.

Yiraqlarga ketme, ezizim,

Baralmaymen, yolliri yiraq.

Çüşlirimge kirginiñ bilen

Oyg்ansam yoq oñumda biraq.

\section{UZAKLARA GITME AZİZiM}

Uzaklara gitme, azizim,

Uzak yerin endişesi çok

Güzel değil ayrı yaşamak

Ayrılanın gözyaşı çok

Uzaklara gitme, azizim,

Varamam arkandan izleyip

Uzak yerde seni düşmanlar

Azdırır: "Biz sana aşığız!" diyerek 
Uzaklara gitme, azizim,

Uzak yerden gelmen zordur

Senin derdinle bu gönlüm

Sen gelinceye kadar sakin değildir

Uzaklara gitme, azizim,

Varamam, yolları uzak,

Düşlerime girmenle

Uyansam fakat yoksun gerçekte

\section{XÉTIÑ KELDI, ÖZÜÑ KELMIDİN}

Xétiñ keldi, özüñ kelmidin,

Tosti kimler séniñ yoluñni.

Düşmen tutsa qandaq çidaymen,

Men tutquçe séniñ qoluñni?!

Xétiñ keldi, özüñ kelmidiñ,

Qonup qaldiñ qaysi öteñde?

Yiğlimamdim bag̀larda yalguz,

Sen kelmiseñ bahar kelgende.

Xétiñ keldi, özüñ kelmidiñ,

Yolliriñda derya barmidu?

Assiqlarniñ teqdir-ezelde

Yaki şundaq yoli tarmidu?

\section{MEKTUBUN GELDİ, KENDIN GELMEDİN}

Mektubun geldi, kendin gelmedin

Kimler kesti senin yolunu

Düşman yakalarsa nasıl dayanırım,

Ben tutunca senin elini?! 
Mektubun geldi kendin gelmedin

Konup kaldın hangi handa?

Ağlamaz mıyım bağlarda yalnız,

Sen gelmesen bahar geldiğinde

Mektubun geldi kendin gelmedin

Yollarında deniz mi var?

Âşıkların kaderi hep

Ya da böyle yolu dar midır?

\section{YAXŞILLAR'ंA NAXŞILAR TOLA}

Derya bolsañ şarqirap aqqin,

Şavquniñni tağlar añlisun.

Yaşalisaq yaşnap yaşayli,

Yüreklerde arman qalmisun.

Tag bolsañmu tekebbur bolma,

Séniñdinmu égiz tağlar bar.

Bügünnimu söyeyli, emma

Buniñdinmu güzel çag̀lar bar.

Östeñ bolsañ, süpsüzük aqqin,

Tekdiñdiki taşlar körünsun.

Yaxşilarni izdep yürgenler

Séni söysün, sendin söyünsün.

Bu dunyada yaxşilar tola,

Yaxşilarġa naxşilar tola.

Kökte quyaş bolalmisaqmu,

Yultuz bolup çaçayli şola. 


\section{IYYILERE ŞARKILAR ÇOK}

Derya isen çağlayıp ak,

Çağıltını dağlar duysun.

Yaşayacaksak çiçeklenip yaşayalım

Yüreğimizde arzu kalmasın.

Dağ isen de kibirlenme, Senden yüce dağlar var.

Bugünü sevelim amma

Bugünden de güzel günler var.

Su kanalıysan berrak ak,

Dibindeki taşlar görünsün

İyileri izleyip yürüyenler

Seni sevsin senden mutlu olsun.

Bu dünyada iyiler çok

İyilere şarkılar çok.

Gökte güneş olamasak da

Yıldız olup saçalım ışık.

\section{Sonuç}

Muhemmetcan Raşidin şiir dünyasına 1950'li yılların sonunda girdiği hâlde asıl önemli eserlerini 1980'li yıllardan sonra kaleme almıştır. Aradaki bu dönem onun haksız yere suçlanıp edebî faaliyetlerden men edildiği kayıp yıllardır. Muhemmetcan Raşidin her şeye rağmen Uygur edebiyatı için önemli bir şahsiyettir. Onun asıl edebî yönünü şiirleri yansıtır. Şiirlerinde aşk, toplum, hayatın güzelliği, insan ve tabiat temalarını sıç̧a kullanır. Hangi temayı seçerse seçsin toplumu, vatan sevgisini o temanın içine ustaca yerleştirir. Bu temaları ele alırken kullandığı dil yalın, samimi ve canlı bir dildir. Kullandığ ve atasözleri diline renk katar. Sanat kaygısı taşımayan benzetmelerle yalın bir üslubu tercih etmiştir. Ancak dilindeki bu yalınlığı basitlik olarak görmemek gerekir. Ġerib-bay (zengin-fakir), aç-toq (aç-tok), yaman-yaxşi (kötü-iyi) gibi 
kelimelerin zıt anlamlarından yararlanması anlatımına güç katan başka bir unsurdur. Kullandığı bu dil okuyucuya hayata farklı bir bakış açısı kazandırırken her okuyucuda yeni bir fikir ve yeni bir heyecan oluşturur. Muhemmetcan Raşidin'in bazı şiirlerinde didaktik bir anlayış görülür. $\mathrm{Bu}$ noktada şiiri toplumun faydasına olacak şekilde kullanmayı prensip edinmiş bir şairdir. Muhemmetcan Raşidin, düşüncelerini sanatıyla harmanlayarak sunabilmiş Çağdaş Uygur edebiyatında önemli bir edebî şahsiyettir.

\section{Kaynakça}

BORATAV, Pertev Naili. (2013), 100 Soruda Türk Folkloru, Ankara: Bilge Su Yayınları.

ÇETIN, Nurullah. ( 2010), Şiir Çözümleme Yöntemi, Ankara: Öncü Kitap Yayınları.

İBRAHIM, Erkin. (2011), AnaTaġlar, Ürümçi: Şincañ Xelq Neşriyati.

KARAMAN, Ahmet. (2011), Lutpulla Mutellip'in Eserleri, Ege Üniversitesi, Türk Dünyası Araştırmaları Enstitüsü, Yayımlanmamış Doktora Tezi, İzmir.

KAŞGARLI, Raile Abdülvahit. (2012), "Komünist Çin Dönemi Uygur Şiiri Üzerine", Türk Dünyası Incelemeleri Dergisi / Journal of Turkish World Studies, Sayı. XII/I, Yaz, s. 345-359.

KOMİSYON. (2006), Uyg்ur Edebiyati Tarixi, Cilt: 4/1, s.386, Pekin: Milletler Neşriyatı.

KOMİSYON. (1999), Uyg̉ur Tiliniñ İzahliq Lugiti (Qisqartilmiş), Ürümçi: Şincan Halk Neşriyatı.

KURBAN, İklil. (1995), Doğu Türkistan İçin Savaş, Ankara: Türk Tarih Kurumu Yayınları. 